\title{
Bernhard BLUMENKRANZ, Juifs et chrétiens dans le monde occidental, 430-1096
}

Paris - Louvain, Peeters, 2007, XIV-440 p.

\section{Capucine Nemo-Pekelman}

\section{(2) OpenEdition \\ 12 Journals \\ Édition électronique \\ URL : http://journals.openedition.org/assr/21103 \\ DOI : $10.4000 /$ assr.21103 \\ ISSN : $1777-5825$ \\ Éditeur \\ Éditions de l'EHESS}

\section{Édition imprimée}

Date de publication : 31 décembre 2009

Pagination : 75-342

ISBN : 978-2-7132-2218-4

ISSN : 0335-5985

Référence électronique

Capucine Nemo-Pekelman, « Bernhard blumenkranz, Juifs et chrétiens dans le monde occidental, 430-1096», Archives de sciences sociales des religions [En ligne], 148 | octobre-décembre 2009, document 148-22, mis en ligne le 19 mai 2009, consulté le 21 septembre 2020. URL : http:// journals.openedition.org/assr/21103; DOI : https://doi.org/10.4000/assr.21103

Ce document a été généré automatiquement le 21 septembre 2020.

(c) Archives de sciences sociales des religions 


\title{
Bernhard BLUMENKRANZ, Juifs et chrétiens dans le monde occidental, 430-1096
}

Paris - Louvain, Peeters, 2007, XIV-440 p.

\author{
Capucine Nemo-Pekelman
}

\section{RÉFÉRENCE}

Bernhard BLUMENKRANZ, Juifs et chrétiens dans le monde occidental, 430-1096, Paris -

Louvain, Peeters, 2007, xIV-440 p.

La réédition de ce maître livre, que l'on ne trouvait plus qu'en bibliothèque, est d'un immense profit pour qui s'intéresse à la thématique des relations entre les juifs et les chrétiens dans l'Occident médiéval. Paru en 1960, Juifs et chrétiens dans le monde occidental, 430-1096 demeure l'ouvrage de référence pour l'époque haut-médiévale avec, pour la période ultérieure des $\mathrm{XII}^{\mathrm{e}}$-XIV ${ }^{\mathrm{e}}$ siècles, le livre de Gilbert Dahan (Les intellectuels chrétiens et les juifs au Moyen Âge, Paris, 1990).

Un premier grand intérêt de Juifs et chrétiens tient à la masse impressionnante du matériau utilisé. On trouve, s'ajoutant aux ouvrages de controverse antijuive proprement dite (traités contra Iudaeos, lettres et dialogues fictifs), des passages isolés recelant des propos polémiques sur les juifs et le judaïsme, que Bernhard Blumenkranz est allé rechercher dans de multiples sources, exégèses bibliques, sermons, témoignages et récits de miracles. L'auteur a d'ailleurs consigné le résultat de ses dépouillements dans des notices rassemblées en un recueil lui-aussi à nouveau disponible (Les auteurs chrétiens latins du Moyen Âge sur les juifs et le judaïsme, ParisLouvain, $c f$. Arch., 142-9, 2007). Les données littéraires sont complétées par des sources juridiques : lois barbares, diplômes, chartes, statuts, constitutions, édits et capitulaires, canons conciliaires et décrétales pontificales. Les collections canoniques sont utilisées, pour la première fois dans ce domaine, comme des sources susceptibles de documenter 
des courants de pensée dans l'Église. De même, l'auteur est le premier à utiliser l'iconographie pour déterminer si les juifs étaient représentés de manière caractérisée (voir également Le Juif médiéval au miroir de l'art chrétien, Paris, 1966). S'ajoutent à cet immense corpus des documents archivistiques (cartulaires, registres) et, enfin, des sources d'origine juive - responsa - qui ne documentent, il est vrai, que la fin de la période étudiée des $\mathrm{X}^{\mathrm{e}}-\mathrm{XI}^{\mathrm{e}}$ siècles.

L'autre intérêt majeur de l'ouvrage réside dans la thèse développée qui, à l'époque où elle fut énoncée, devait bouleverser l'image classique que l'on se faisait des rapports judéo-chrétiens au Moyen Âge. L'auteur invite à distinguer un premier d'un second Moyen Âge, assurant que le sombre tableau habituellement dépeint ne concernerait que la situation née de la période faisant suite à la Première Croisade (1096). Avant cette date, juifs et chrétiens ordinaires auraient vécu dans des rapports quotidiens de relative bonne entente. Il en aurait été de même pour les " intellectuels ", dont les divergences n'auraient généralement pas dépassé le stade de la controverse, controverse menée pour les besoins de la mission et impulsée, si l'on se replace dans les mentalités de l'époque, par des sentiments généreux puisqu'il s'agissait d'aider l'autre à accéder à la vérité. Les juifs n'auraient d'ailleurs eux-mêmes pas hésité, quand ils en avaient l'occasion - notamment avec les chrétiens et païens de leur domesticité -, à faire du prosélytisme. L'auteur admet une exception à cette image pacifiée, celle de la période catholique de l'Espagne wisigothique. À partir du quatrième concile de Tolède (633), pouvoirs ecclésiastique et séculier s'allièrent dans une politique missionnaire violente débouchant sur une persécution antijuive qui ne cessa qu'à la chute du royaume. Mais dans les autres régions d'Occident (correspondant à la France, l'Italie, l'Angleterre et l'Allemagne actuelles), la mission aurait pris la forme d'incitations matérielles à la conversion et, seulement dans des cas isolés, de menaces plus sévères. La portée des campagnes de baptêmes forcés, documentées en Gaule mérovingienne, se trouve donc minimisée, quand l'auteur ne met pas en doute la véracité des récits qui les rapportent. Seuls les juristes de l'Église auraient tenté, par le levier du droit, de stigmatiser les juifs en les plaçant à l'écart du corps civique par la création de statuts juifs, mais ils ne seraient parvenus à engager le pouvoir séculier avec eux qu'à l'extrême terme de la période envisagée.

L'ouvrage est construit en quatre parties composant les étapes de cette démonstration: les rapports de bon voisinage; la concurrence missionnaire; la polémique judéo-chrétienne ; enfin, la déchéance légale.

Juifs et chrétiens auraient donc entretenu des rapports de bon voisinage, les juifs n'ayant formé de groupe distinct ni par la langue (ils parlaient la langue du pays et le latin, l'hébreu étant réservé à un usage cultuel et culturel), ni par les noms qu'ils portaient (on compte autant de noms bibliques chez les ecclésiastiques que chez les juifs et, à l'inverse, les juifs portent des noms bibliques latinisés et des noms grecs et locaux). Par ailleurs, les monuments d'art ne les représentent jamais sous les traits stigmatisants que l'on verra apparaître à partir du XII ${ }^{\mathrm{e}}$ siècle. Il n'y a pas, non plus, de métiers spécifiquement juifs. Les juifs n'ont nullement le monopole du commerce international et pas davantage celui de la traite des esclaves. La fréquence de mentions signalant des marchands juifs s'explique par l'importance, au début du Moyen Âge, de la fonction de marchands de cour, certains juifs ayant endossé le rôle de fournisseurs quasi-officiels des princes. Les juifs ont en revanche exercé des activités agricoles, et l'auteur recense une masse d'exploitations agricoles et de propriétés foncières leur 
ayant appartenu, en Italie, en Espagne wisigothique, en Allemagne et en France. L'intégration des juifs parmi les autres populations se donne aussi à voir dans les villes, aucun quartier ne leur étant spécialement attribué. Au niveau politique, les juifs sont des citoyens fournissant un service armé, certains étant même introduits comme conseillers dans les cercles $d u$ pouvoir. Cette proximité constatée donne tout naturellement lieu à quelques syncrétismes et mouvements judaïsants. Ainsi ce juif priant un saint guérisseur et cet autre élevant un autel au prophète Elie, ou ces chrétiens chômant les jours de shabbat, respectant certains préceptes alimentaires et hésitant à se faire circoncire.

Dans une deuxième partie, l'auteur aborde ce qu'il appelle «la concurrence missionnaire » pour souligner que, loin d'être subi par les juifs, le prosélytisme était réciproque. Au-delà des arguments intellectuels fondés sur la ratio et l'auctoritas, le camp chrétien n'hésitait pas à laisser entrevoir des avantages matériels aux candidats à la conversion. Les restrictions imposées au culte juif peuvent aussi être envisagées comme des tentatives pour pousser au baptême. Mais l'auteur refuse de compter au nombre des baptêmes forcés ceux qui sont réalisés sous la menace de la confiscation des biens ou de l'exil, la notion de coercition s'entendant, chez les anciens, de manière plus restrictive et moins nuancée que chez les modernes. On peut, en revanche, parler de mission violente en Espagne wisigothique, où le baptême est, en 613, imposé sous menace de mort et où, par la suite, sont poursuivis sans relâche les " judaïsants ", c'està-dire les juifs convertis de force et revenus au judaïsme. Le débat, organisé ou spontané, est documenté par une littérature abondante mettant en scène des acteurs démontrant souvent une réelle curiosité de l'autre: des sources documentent ainsi, pour une exégèse biblique, la consultation par des intellectuels chrétiens de rabbins et réciproquement, les rabbins paraissent documentés sur le christianisme au travers de la contradiction qu'ils lui opposent et des emprunts matériels qu'ils lui font. Le judaïsme du haut Moyen Âge est décrit comme un « organisme en bonne santé » qui, de ce fait, ne se trouve pas dans une position de repli mais d'offensive. Les juifs mèneraient un prosélytisme actif auprès, notamment mais pas uniquement, de personnes économiquement inférieures se trouvant dans des rapports de dépendance envers eux - serviteurs, journaliers et esclaves. C'est ce phénomène qu'il faudrait lire en creux au travers des textes de lois - il est vrai nombreux et répétés - prohibant la présence de non-juifs dans la domesticité des juifs et multipliant les mises en garde contre leur fréquentation (repas communs en particulier). C'est ce que révèleraient également les histoires retentissantes de conversions au judaïsme, comme celle du diacre de Louis le Pieux Bodo devenu Eléazar, qui seraient le symptôme d'un phénomène plus vaste de conversions anonymes.

Dans une troisième partie, l'auteur aborde le contenu de la polémique théologique entre les chrétiens et leurs interlocuteurs juifs. La question du texte formant la base de la discussion se pose avant toute discussion au fond, les juifs ne reconnaissant pas l'autorité des textes sacrés chrétiens (Évangiles et traduction des Septante), rejetant certains livres du canon biblique, et accusant les chrétiens, qui leur renvoient la pareille, d'avoir falsifié certains passages des Écritures. Sur le fond, la discussion tourne principalement autour des exégèses chrétiennes de l'Ancien Testament tendant à découvrir, en tout endroit, une annonce du Christ et de l'Église. Ainsi, sont jugées outrancières par les juifs les interprétations christologiques de Gn 1,26 et 24,4 ; de Dt 21,23 ; d'Is 7,14 et 9,5; d'Ez 44,2 sqq. Le verset Gn 49,10: «Il ne manquera pas de roi de Juda ni de prince de sa descendance jusqu'à ce que vienne celui 
qui doit être envoyé, et celui-ci sera l'attente des peuples » est notamment très discuté, car les polémistes chrétiens croient pouvoir retirer de la disparition effective du royaume juif la preuve de la venue du Messie. B. Blumenkranz isole huit lieux principaux de l'affrontement entre l'Église et la Synagogue du haut Moyen Âge: le thème de la Loi juive qui, ayant été abolie et accomplie par la venue du Christ, aurait perdu sa valeur péremptoire ; celui de l'attente juive du Messie (les calculs de la date de sa venue et la recherche de signes sont tournés en dérision par les adversaires chrétiens qui se plaisent à rappeler quelques déceptions subies par des juifs abusés par de faux messies) ; les thèmes de l'Incarnation et de la naissance virginale, scandales au yeux des juifs pour qui la perfection divine ne saurait être compatible avec la condition humaine de Jésus dont la vie est, à partir du premier quart $d u$ IX ${ }^{e}$ siècle, moquée au travers de la littérature des Toledoth Yeshu; le dogme trinitaire, particulièrement attaqué par les juifs en ce qu'il serait incompatible avec la foi monothéiste revendiquée par le christianisme ; l'élection des Gentils, vrais juifs et vrai Israël, et la déchéance des juifs que prouverait leur situation politique contemporaine de dispersion et d'assujettissement aux chrétiens ; enfin, la crucifixion, dont la responsabilité se trouve imputée aux juifs à l'exclusion du pouvoir romain, et dont il semblerait que les juifs de l'époque se soient eux-mêmes prévalus puisqu'elle constituait à leurs yeux une preuve de plus du caractère strictement humain de Jésus.

Erfin, la quatrième partie traite de la condition juridique des juifs. Si les chrétiens ordinaires ou les intellectuels entretiennent des relations pacifiques avec leurs voisins et interlocuteurs juifs, il n'en est pas de même pour les juristes de l'Église qui, ayant une tendance naturelle à bâtir des classifications rigides, tentent de concrétiser en droit la posture théologique chrétienne. Héritée de l'Empire romain, la situation juridique des juifs dans les royaumes romano-barbares, régis par le système de la personnalité des lois, était celle des Romani. Intégrés en cette qualité dans l'ordonnancement juridique, ils étaient loin, contrairement à ce qu'affirme une historiographie tendancieuse, d'avoir le statut d'étrangers. Or les juristes de l'Église vont tenter de convaincre les autorités séculières d'enfermer les juifs dans un statut à part. En Espagne wisigothique, d'abord, fut élaboré, à partir du quatrième concile de Tolède (633), un statut juif qui devait conduire à leur marginalisation et à leur persécution, le pouvoir séculier s'étant investi très activement dans une politique missionnaire. En Gaule carolingienne ensuite, furent réalisés, par l'évêque de Lyon Agobard, son secrétaire Florus et son successeur Amolon, plusieurs projets de statuts juifs ; adoptés par les pères du concile de Meaux-Paris, ils demeurèrent pourtant lettremorte faute d'avoir été transcrits dans le droit séculier, le soutien de Charles le Chauve ayant manqué. Selon B. Blumenkranz, l'échec de ces tentatives se trouverait confirmé par la teneur des collections canoniques ayant circulé dans l'empire carolingien entre le $\mathrm{IX}^{\mathrm{e}}$ et le début du $\mathrm{XI}^{\mathrm{e}}$ siècle, qui ne comprendraient plus les rubriques anciennes spécialement consacrées aux juifs. Lorsque de telles rubriques subsistent, elles ne seraient plus composées que de textes correspondant à une tendance clémente traditionnellement représentée par le pape du vi siècle, Grégoire le Grand, les canons violemment antijuifs des conciles wisigothiques n'ayant jamais franchi les frontières de la péninsule ibérique. L'auteur utilise toujours la source des collections canoniques pour confirmer le changement profond intervenu, selon lui, dans la condition des juifs depuis la Première Croisade de 1096. C'est ainsi que le Décret de Burchard de Worms (1008-1012) fonde son attitude juridique sur les Moralia de Grégoire le Grand tandis que la collection d'Yves de Chartres (1094) adopte un ton fort différent, citant un texte 
antijuif du traité pseudo-augustinien De fide ad Petrum et redécouvrant une série de canons vexatoires oubliés des collections médiévales antérieures. B. Blumenkranz insère ce durcissement dans le contexte d'une transformation plus générale des systèmes juridiques du haut Moyen Âge, qui glissent du régime de la personnalité des lois, régime de pluralisme juridique dans lequel les juifs n'auraient formé qu'un groupe parmi tant d'autres, à celui de la territorialité des lois, qui voient s'unifier les droits au sein d'un même espace, faisant apparaître un "particularisme » juif. Enfin, l'auteur procède à une analyse du contenu des législations séculière et ecclésiastique concernant les juifs, dont il détache les thèmes suivants: la pratique du judaïsme (prières, shabbat et fêtes, lois alimentaires, statut des synagogues, livres et objets liturgiques), pratique qui se trouve à peine entravée; la législation sur le mariage interdisant les unions matrimoniales entre juifs et chrétiens; les atteintes à certains aspects de l'autorité paternelle et aux droits filiaux; la très dense et complexe législation sur la possession d'esclaves païens ou chrétiens et sur le personnel domestique libre ; la fermeture des emplois publics ; les restrictions frappant certains commerces, objets liturgiques chrétiens et du vin par souci de pureté rituelle; les tentatives vaines d'atteintes à la propriété foncière; enfin, la situation du justiciable juif devant les tribunaux juifs et non juifs quant à la procédure en vigueur et, sur certains aspects du droit criminel, quant au fond du droit applicable.

On constate, in fine, que la question des relations entre juifs et chrétiens au début du Moyen Âge est abordée sous de très nombreux aspects. Chacun de ces aspects - controverse théologique, vie économique et sociale des juifs, pensée et culture juives, présence archéologique, art chrétien sur les juifs, condition juridique, histoire politique des juifs dans les différents pays envisagés - constituent aujourd'hui des champs spécialisés que Juifs et chrétien a souvent inaugurés. Concernant, par exemple, la situation juridique des juifs et leurs rapports avec le pouvoir, Juifs et chrétiens a proposé des analyses stimulantes, et que la recherche actuelle a remises à jour dans le sens, parfois, de la contradiction. Brian Brennan, Michel Rouche et Bruno Dumézil ont ainsi reconstitué toute la violence des persécutions intervenues en Gaule mérovingienne à partir de la moitié $\mathrm{du} \mathrm{vI}$ e siècle, ce qui nuance la vision optimiste du livre sur la période. À l'inverse, John Gilchrist a fortement minimisé l'incidence, en dehors des terres où elle est passée, de la Première Croisade sur l'histoire des juifs, et propose de pousser plus loin que 1096 le point de départ d'une détérioration de leur situation. De même faudrait-il revoir les causes de la marginalisation juridique des juifs - si elle eut vraiment lieu - depuis qu'une historiographie récente a complexifié la thèse d'un passage du régime de la personnalité à la territorialité des lois. Juifs et chrétiens demeure donc toujours, cinquante ans après, une base d'étude incontournable. À quoi nous ajouterons que sa lecture, extrêmement agréable, laisse deviner, derrière le savant, un homme d'un humanisme sincère dont l'œuvre témoigne aussi d'une autre histoire, celle de la reconstruction des relations judéo-chrétiennes après l'Holocauste des juifs européens. 